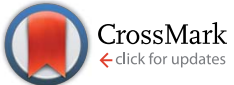

Cite this: RSC Adv., 2017, 7, 47

Received 7th November 2016 Accepted 22nd November 2016

DOI: $10.1039 / \mathrm{c} 6 \mathrm{ra2} 6429 \mathrm{~h}$

\section{Synthesis of aryl triflones by insertion of arynes into $\mathrm{C}-\mathrm{SO}_{2} \mathrm{CF}_{3}$ bonds $\uparrow$}

\author{
Xian Zhao, ${ }^{a}$ Yangen Huang, ${ }^{a}$ Feng-Ling Qing ${ }^{a b}$ and Xiu-Hua $X u^{\star b}$ \\ A new approach toward the synthesis of aryl triflones was achieved by the formal insertion of arynes into $\mathrm{C}$ - \\ $\mathrm{SO}_{2} \mathrm{CF}_{3}$ bonds. This reaction proceeds through addition of $\mathrm{CF}_{3} \mathrm{SO}_{2}$-containing nucleophiles to the in situ \\ generated arynes and subsequent intramolecular rearrangement.
}

www.rsc.org/advances

Largely as a result of their unique biological properties, fluorinated compounds have found wide applications in pharmaceuticals, agrochemicals, and materials. ${ }^{1}$ Compounds containing a trifluoromethanesulfonyl (triflyl, $\mathrm{SO}_{2} \mathrm{CF}_{3}$, Tf) group have received increasing interest due to the strong electronwithdrawing ability and high lipophilicity of $\mathrm{SO}_{2} \mathrm{CF}_{3} .{ }^{2}$ In particular, aryl triflones $\left(\mathrm{ArSO}_{2} \mathrm{CF}_{3}\right)$ are frequently used as structural units in bioactive compounds, ${ }^{3}$ catalysts or ligands, ${ }^{4}$ and advanced functional materials. ${ }^{5}$ Consequently, a number of methods have been developed for the preparation of aryl triflones. The general methods include oxidation of aryl trifluoromethyl sulfides, ${ }^{6}$ trifluoromethylation of aryl sulfonyl fluorides or aryl sulfinates, ${ }^{7}$ and triflylation of aromatic compounds. ${ }^{8}$

In 2003, Lloyd-Jones and co-workers reported an unprecedented method for the preparation of aryl triflones by anionic thia-Fries rearrangement of aryl triflates (Scheme 1a). ${ }^{9 a}$ Since then, Lloyd-Jones' group and Butenschön's group have applied this rearrangement reaction to the synthesis of various $o$ hydroxyaryl triflones. ${ }^{4 d, 9}$ Recently, one of the present authors together with collaborators synthesized a series of heteroaryl triflones with the same methodology (Scheme 1b)..$^{10}$ In these anionic thia-Fries rearrangement reactions, the carbanion intermediates are generated via directed ortho-metalation with organolithium reagents, which are not tolerant of a range of functional groups. We wondered if it was possible to develop new methods to generate carbanions under mild conditions. Considering that the addition of a nucleophile to the aryne is a general method to generate a transient aryl anion intermediate, ${ }^{11}$ we reasoned that the reaction of a Tf-containing

${ }^{a}$ College of Chemistry, Chemical Engineering and Biotechnology, Donghua University, 2999 North Renmin Lu, Shanghai 201620, China

${ }^{b}$ Key Laboratory of Organofluorine Chemistry, Shanghai Institute of Organic Chemistry, Chinese Academy of Science, 345 Lingling Lu, Shanghai 200032, China. E-mail:xuxiuhua@sioc.ac.cn

$\dagger$ Electronic supplementary information (ESI) available. CCDC 1509106. For ESI and crystallographic data in CIF or other electronic format see DOI: $10.1039 / \mathrm{c} 6 \mathrm{ra} 26429 \mathrm{~h}$ nucleophile and the aryne would give the Tf-containing carbanion intermediate, which may subsequently undergo anionic thia-Fries rearrangement to afford the corresponding aryl triflone. Interestingly, during the investigation of our idea, $\mathrm{Li}$ and co-workers reported a novel synthesis of $o$-aminoaryl triflones from $N$-triflylated anilines and arynes by adopting a similar strategy (Scheme 1c). ${ }^{12}$ As a continuation of our research interest in triflyl chemistry, ${ }^{10,13}$ we herein disclose the first example of preparation of $o$-alkylaryl triflones by the insertion of arynes into $\mathrm{C}-\mathrm{SO}_{2} \mathrm{CF}_{3}$ bond through the tandem nucleophilic attack/intramolecular rearrangement (Scheme 1d).

The insertion of arynes into element-element bonds, such as carbon-carbon, ${ }^{14}$ carbon-heteroatom, ${ }^{15}$ and heteroatomheteroatom ${ }^{16}$ bonds, provides a convenient method for direct access to 1,2-disubstituted aromatics. However, this method has rarely been applied to synthesize $\mathrm{SO}_{2} \mathrm{CF}_{3}$-containing aromatics. ${ }^{12,17}$ Thus, we chose 2 -(trimethylsilyl)phenyltriflate (1a) and 4-(((trifluoromethyl)sulfonyl)methyl)benzonitrile (2a) as the model substrates to explore the alkylation-triflylation of

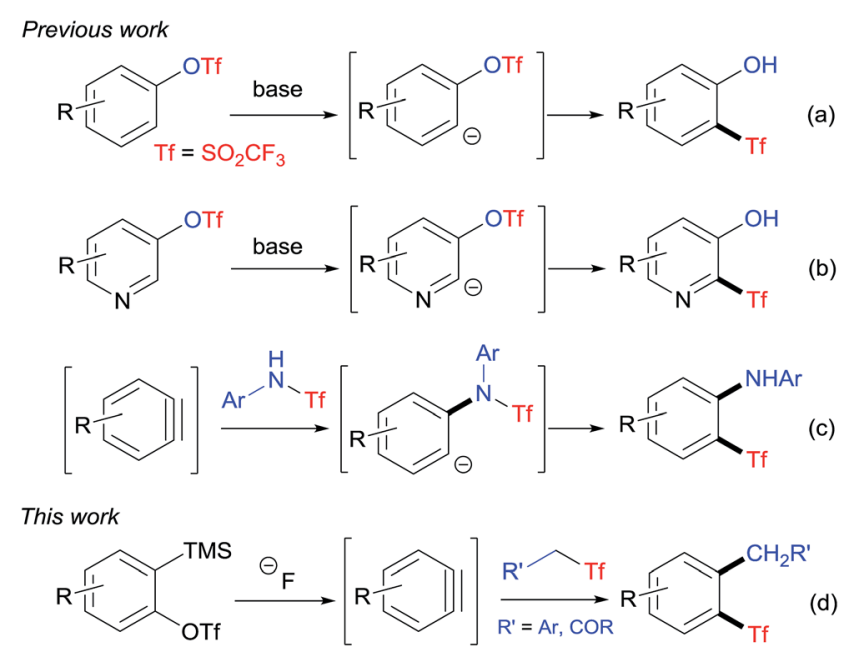

Scheme 1 Preparation of (hetero)aryl triflones through anionic thiaFries rearrangement. 
arynes for the preparation of $o$-alkylaryl triflones (Table 1). Initially, different fluoride sources, including CsF, KF, tetrabutylammonium fluoride (TBAF), and KF/18-crown-6, were explored employing THF as the solvent (entries 1-4). Among them, KF/18-crown- 6 proved to be the optimal fluoride source, leading to desired product $3 \mathbf{a}$ in $60 \%$ yield (entry 4 ). In the subsequent solvent screen, we found that the use of other solvents such as $\mathrm{MeCN}$, toluene, dioxane, and $\mathrm{Et}_{2} \mathrm{O}$ diminished the yield of 3a (entries 5-8). Furthermore, increasing the temperature to $50{ }^{\circ} \mathrm{C}$ could slightly improve the yield to $75 \%$ (entry 9). However, when the reaction was performed at $70{ }^{\circ} \mathrm{C}$, lower yield was obtained (entry 10). Additional surveys of the reaction stoichiometry (entries 11-14) revealed that the instance with $1 \mathrm{a}$ as the limiting reagent, 1.0 equivalent of $2 \mathrm{a}, 2.0$ equivalents of $\mathrm{KF}$, and 2.0 equivalents of 18-crown- 6 afforded the highest yield of $3 a$ (entry 12). Finally, increasing or reducing the concentration of this reaction had no positive effects on the yield (entries 15 and 16).

With the optimized reaction conditions (Table 1, entry 12) in hand, we then investigated the substrate scope of this reaction. The reaction of aryne precursor 1a with substituted benzyl triflones 2 carried out effectively to give the corresponding $o$ alkylaryl triflones $\mathbf{3 a - k}$ in moderate to excellent yields

Table 1 Optimization of reaction conditions ${ }^{a}$

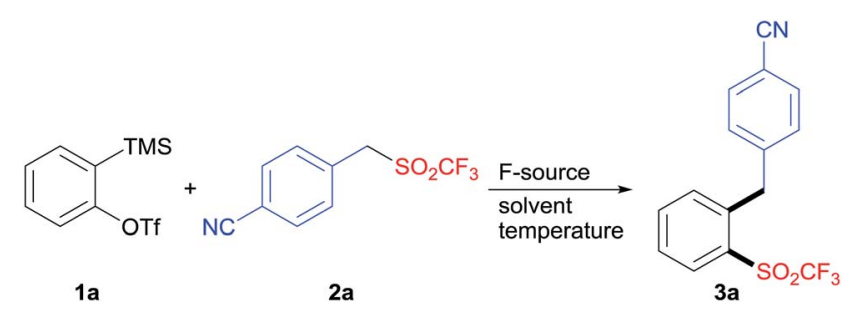

\begin{tabular}{|c|c|c|c|c|}
\hline Entry & F-Source & Solvent & Temperature & Yield $^{b}(\%)$ \\
\hline 1 & CsF & THF & $\mathrm{rt}$ & Trace \\
\hline 2 & $\mathrm{KF}$ & THF & $\mathrm{rt}$ & 10 \\
\hline 3 & TBAF & THF & $\mathrm{rt}$ & 49 \\
\hline 4 & KF/18-crown-6 & THF & $\mathrm{rt}$ & 60 \\
\hline 5 & KF/18-crown-6 & MeCN & $\mathrm{rt}$ & 24 \\
\hline 6 & KF/18-crown-6 & Toluene & $\mathrm{rt}$ & 5 \\
\hline 7 & KF/18-crown-6 & Dioxane & $\mathrm{rt}$ & 45 \\
\hline 8 & KF/18-crown-6 & $\mathrm{Et}_{2} \mathrm{O}$ & $\mathrm{rt}$ & 51 \\
\hline 9 & KF/18-crown-6 & THF & $50^{\circ} \mathrm{C}$ & 75 \\
\hline 10 & KF/18-crown-6 & THF & $70^{\circ} \mathrm{C}$ & 54 \\
\hline $11^{c}$ & KF/18-crown-6 & THF & $50{ }^{\circ} \mathrm{C}$ & 73 \\
\hline $12^{d}$ & KF/18-crown-6 & THF & $50^{\circ} \mathrm{C}$ & 85 \\
\hline $13^{e}$ & $\mathrm{KF} / 18$-crown-6 & THF & $50^{\circ} \mathrm{C}$ & 30 \\
\hline $14^{f}$ & KF/18-crown-6 & THF & $50{ }^{\circ} \mathrm{C}$ & 60 \\
\hline $15^{g}$ & KF/18-crown-6 & THF & $50{ }^{\circ} \mathrm{C}$ & 69 \\
\hline $16^{h}$ & KF/18-crown-6 & THF & $50^{\circ} \mathrm{C}$ & 78 \\
\hline
\end{tabular}

${ }^{a}$ Reaction conditions: $1 \mathrm{a}(0.10 \mathrm{mmol}), 2 \mathrm{a}(0.15 \mathrm{mmol})$, fluoride source $(0.20 \mathrm{mmol})$, solvent $(3.0 \mathrm{~mL})$, under $\mathrm{N}_{2}$, temperature, overnight. ${ }^{b}$ Yields determined by ${ }^{19} \mathrm{~F}$ NMR spectroscopy using trifluoromethoxybenzene as an internal standard. ${ }^{c}$ 2a $(0.12 \mathrm{mmol})$. ${ }^{d}$ 2a $(0.10 \mathrm{mmol}) .{ }^{e} \mathrm{KF}(0.10 \mathrm{mmol}), 18$-crown-6 $(0.10 \mathrm{mmol}) .{ }^{f} \mathrm{KF}$ (0.30 mmol), 18-crown-6 (0.30 mmol). ${ }^{g}$ THF $(1.5 \mathrm{~mL}) .{ }^{h}$ THF $(5.0 \mathrm{~mL})$.

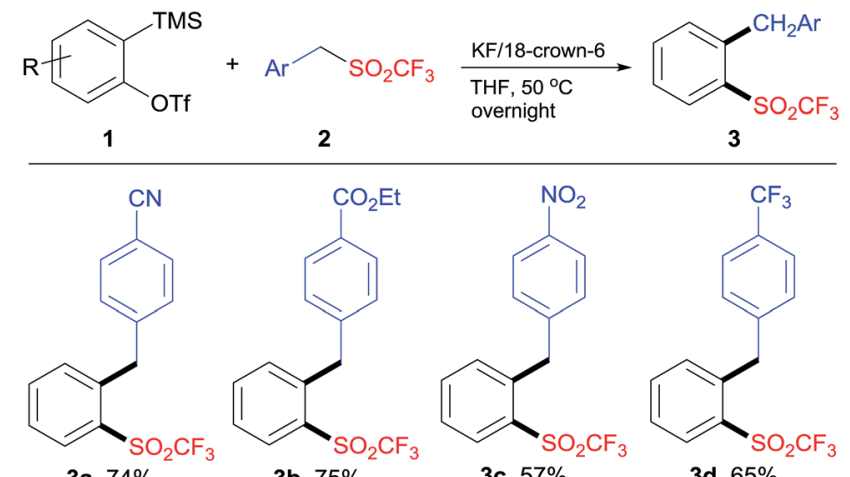

3a, $74 \%$

3b, $75 \%$

3c, $57 \%$

3d, $65 \%$
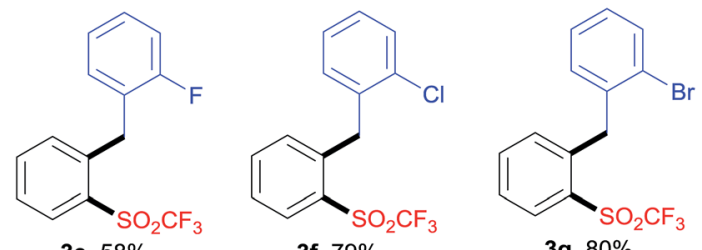

$$
\text { 3e, } 58 \%
$$

$$
\text { 3f, } 79 \%
$$

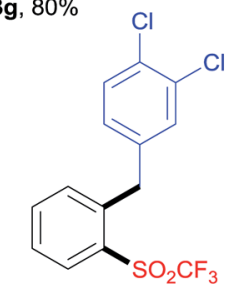

3j, $41 \%$

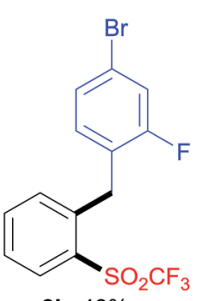

3k, $48 \%$

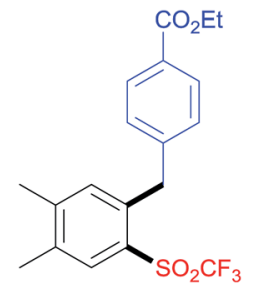

3I, $50 \%$

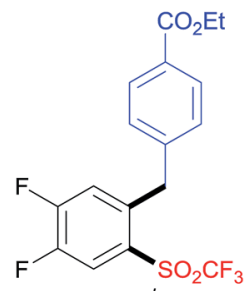

$3 \mathrm{~m}, 31 \%^{b}$
Scheme 2 The reaction of 2-(trimethylsilyl)aryl triflates and benzyl triflones. ${ }^{a}{ }^{a}$ Reaction conditions: 1 ( $\left.0.30 \mathrm{mmol}\right), 2$ (0.30 mmol), KF (0.60 mmol), 18-crown-6 (0.60 mmol), THF $(9.0 \mathrm{~mL})$, under $\mathrm{N}_{2}, 50{ }^{\circ} \mathrm{C}$, overnight, isolated yields. ${ }^{b}$ Yield determined by ${ }^{19} \mathrm{~F}$ NMR spectroscopy using trifluoromethoxybenzene as an internal standard.

(Scheme 2). In general, the electron-withdrawing substituent on benzyl triflones was essential for this transformation. Benzyl triflones bearing fluoro (2e), chloro (2f), and bromo (2g) groups were suitable substrates, providing products $\mathbf{3 e}-\mathbf{g}$ in good yields. The steric hindrance had no obvious effect on the yield, as benzyl triflone $\mathbf{2 h}$ proceeded well to afford $\mathbf{3 h}$ in high yield. Benzyl triflone $2 \mathbf{i}$ with a substituent into the meta position of the benzyl scaffold was also effective. In addition, disubstituted triflones $\mathbf{2 j}$ and $\mathbf{2 k}$ underwent this reaction smoothly. It was noteworthy that benzyl triflone $\mathbf{2 b}$ reacted with aryne precursors $\mathbf{1 b}$ and 1c to produce the corresponding insertion products $\mathbf{3 l}$ and $\mathbf{3 m}$. The structure of product $\mathbf{3}$ was confirmed by X-ray crystallographic analysis of compound $\mathbf{3 a}$ (see the ESI $\dagger$ ).

To extend the scope of this protocol, we further examined other $\mathrm{CF}_{3} \mathrm{SO}_{2}$-containing substrates. In a similar manner, the reaction of $1 \mathbf{a}$ with $\beta$-triflyl esters $\mathbf{4 a}$ or $\mathbf{4 b}$ gave the desired 

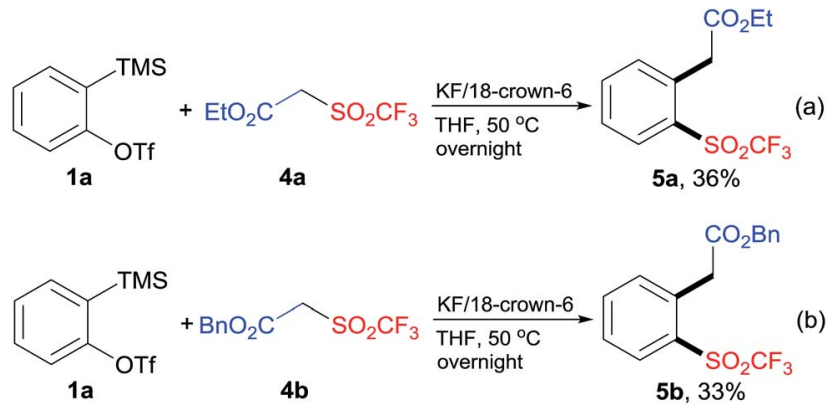

Scheme 3 The reaction of $1 \mathrm{a}$ and $\beta$-triflyl esters.

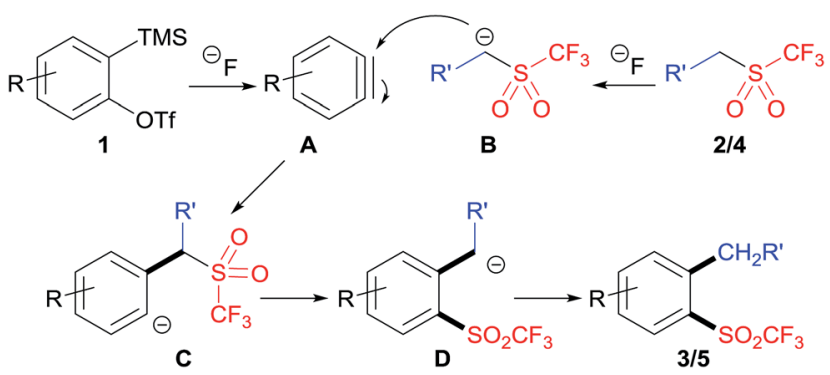

Scheme 4 Proposed reaction mechanism.

products $\mathbf{5 a}$ and $\mathbf{5 b}$, albeit in low yields (Scheme 3). Some unknown byproducts ( $<10 \%$ yield) were also obtained. In the cases of $\beta$-triflyl amides, the yields of the desired products were even lower. Furthermore, when $\beta$-triflyl ketones were subjected to the standard reaction conditions, the insertion of arynes into $\mathrm{C}-\mathrm{SO}_{2} \mathrm{CF}_{3}$ bond did not happen. Instead, the insertion of arynes into $\mathrm{C}$ (active methylene)-C(ketone) bond was detected.

A plausible mechanism of this reaction is proposed in Scheme 4. The substrates 2-(trimethylsilyl)aryltriflate $\mathbf{1}$ and $\mathrm{CF}_{3} \mathrm{SO}_{2}$-containing nucleophile $2 / 4$ were respectively converted to aryne $\mathbf{A}$ and carbanion $\mathbf{B}$ under the treatment of fluoride anion. Then, the addition of $\mathbf{B}$ to $\mathbf{A}$ afforded intermediate $\mathbf{C}$, which underwent intramolecular migration of the triflyl group to give intermediate $\mathbf{D}$. Finally, protonation of intermediate $\mathbf{D}$ gave the target product $\mathbf{3} \mathbf{5}$. It should be noted that the triflyl group plays an important role in this reaction. The analogous reaction of aryne precursors with substituted benzyl methanesulfones could not give the desired aryl methanesulfones.

In conclusion, we have developed a new access to aryl triflones starting from aryne precursors and $\mathrm{CF}_{3} \mathrm{SO}_{2}$-containing nucleophiles. This protocol proceeds through the tandem nucleophilic attack/intramolecular rearrangement to give the formal insertion products. Further exploration of this insertion reaction in the preparation of bioactive fluorinated compounds is in progress.

\section{Acknowledgements}

We are grateful for the financial support from National Natural Science Foundation of China (21502215, 21421002, 21332010, 21272036), Strategic Priority Research Program of the Chinese
Academy of Sciences (XDB20020000), Youth Innovation Promotion Association CAS (2016234), and Shanghai Pujiang Program (15PJ1410300).

\section{Notes and references}

1 (a) K. Müller, C. Faeh and F. Diederich, Science, 2007, 317, 1881; (b) S. Purser, P. R. Moore, S. Swallow and V. Gouverneur, Chem. Soc. Rev., 2008, 37, 320; (c) N. A. Meanwell, J. Med. Chem., 2011, 54, 2529; (d) M. Cametti, B. Crousse, P. Metrangolo, R. Milani and G. Resnati, Chem. Soc. Rev., 2012, 41, 31; (e) J. Wang, M. Sánchez-Roselló, J. L. Aceña, C. del Pozo, A. E. Sorochinsky, S. Fustero, V. A. Soloshonok and H. Liu, Chem. Rev., 2014, 114, 2432; (f) E. P. Gillis, K. J. Eastman, M. D. Hill, D. J. Donnelly and N. A. Meanwell, J. Med. Chem., 2015, 58, 8315.

2 (a) W. Sheppard, J. Am. Chem. Soc., 1963, 85, 1314; (b) C. Hansch, A. Leo and R. W. Taft, Chem. Rev., 1991, 91, 165; (c) R. Goumont, E. Kizilian, E. Buncel and F. Terrier, Org. Biomol. Chem., 2003, 1, 1741; (d) F. Terrier, E. Magnier, E. Kizilian, C. Wakselman and E. Buncel, J. Am. Chem. Soc., 2005, 127, 5563.

3 (a) G. Wang, H. Zhang, J. Zhou, C. Ha, D. Pei and K. Ding, Synthesis, 2008, 2398; (b) B. E. Sleebs, P. E. Czabotar, W. J. Fairbrother, W. D. Fairlie, J. A. Flygare, D. C. S. Huang, W. J. A. Kersten, M. F. T. Koehler, G. Lessene, K. Lowes, J. P. Parisot, B. J. Smith, M. L. Smith, A. J. Souers, I. P. Street, H. Yang and J. B. Baell, J. Med. Chem., 2011, 54, 1914; (c) P. Ondachi, A. Castro, C. W. Luetje, M. I. Damaj, S. W. Mascarella, H. A. Navarro and F. I. Carroll, J. Med. Chem., 2012, 55, 6512; (d) J. Chen, H. Zhou, A. Aguilar, L. Liu, L. Bai, D. McEachern, C.-Y. Yang, J. L. Meagher, J. A. Stuckey and S. Wang, J. Med. Chem., 2012, 55, 8502.

4 (a) K. Ishihara, A. Hasegawa and H. Yamamoto, Angew. Chem., Int. Ed., 2001, 40, 4077; (b) P. Wu, R. Hilgraf and V. V. Fokin, Adv. Synth. Catal., 2006, 348, 1079; (c) A. Hasegawa, Y. Naganawa, M. Fushimi, K. Ishihara and H. Yamamoto, Org. Lett., 2006, 8, 3175; (d) R. Kargbo, Y. Takahashi, S. Bhor, G. R. Cook, G. C. Lloyd-Jones and I. R. Shepperson, J. Am. Chem. Soc., 2007, 129, 3846; (e) H. Yanai, H. Ogura, H. Fukaya, A. Kotani, F. Kusu and T. Taguchi, Chem.-Eur. J., 2011, 17, 11747; (f) H. Yanai, T. Yoshino, M. Fujita, H. Fukaya, A. Kotani, F. Kusu and T. Taguchi, Angew. Chem., Int. Ed., 2013, 52, 1560.

5 (a) C. L. Droumaguet, O. Mongin, M. H. V. Werts and M. Blanchard-Desce, Chem. Commun., 2005, 2802; (b) O. Mongin, L. Porrès, M. Charlot, C. Katan and M. Blanchard-Desce, Chem.-Eur. J., 2007, 13, 1481; (c) F. Terenziani, C. L. Droumaguet, C. Katan, O. Mongin and M. Blanchard-Desce, ChemPhysChem, 2007, 8, 723; (d) C. Rouxel, C. L. Droumaguet, Y. Macé, S. Clift, O. Mongin, E. Magnier and M. Blanchard-Desce, Chem.-Eur. J., 2012, 18, 12487.

6 (a) Q.-Y. Chen and J.-X. Duan, J. Chem. Soc., Chem. Commun., 1993, 918; (b) M. E. González-Núñez, R. Mello, J. Royo, 
J. V. Ríos and G. Asensio, J. Am. Chem. Soc., 2002, 124, 9154; (c) L. Xu, J. Cheng and M. L. Trudell, J. Org. Chem., 2003, 68, 5388; (d) P. Kirsch, M. Lenges, D. Kühne and K.-P. Wanczek, Eur. J. Org. Chem., 2005, 797; (e) R. Pluta, P. Nikolaienko and M. Rueping, Angew. Chem., Int. Ed., 2014, 53, 1650.

7 (a) R. P. Singh, G. Cao, R. L. Kirchmeier and J. M. Shreeve, J. Org. Chem., 1999, 64, 2873; (b) Y. Chang and C. Cai, J. Fluorine Chem., 2005, 126, 937; (c) L. M. Yagupolskii, A. V. Matsnev, R. K. Orlova, B. G. Deryabkin and Y. L. Yagupolskii, J. Fluorine Chem., 2008, 129, 131; (d) X. Lin, G. Wang, H. Li, Y. Huang, W. He, D. Ye, K.-W. Huang, Y. Yuan and Z. Weng, Tetrahedron, 2013, 69, 2628; (e) G. K. S. Prakash, F. Wang, Z. Zhang, R. Haiges, M. Rahm, K. O. Christe, T. Mathew and G. A. Olah, Angew. Chem., Int. Ed., 2014, 53, 11575.

8 (a) J. B. Hendrickson and K. W. Bair, J. Org. Chem., 1977, 42, 3875; (b) X. Creary, J. Org. Chem., 1980, 45, 2727; (c) A. P. Avdeenko, S. A. Konovalova, O. N. Mikhailichenko, S. V. Shelyazhenko, V. V. Pirozhenko and L. M. Yagupol'skii, Russ. J. Org. Chem., 2012, 48, 221; (d) S. C. Cullen, S. Shekhar and N. K. Nere, J. Org. Chem., 2013, 78, 12194; (e) S. K. Aithagani, K. R. Yempalla, G. Munagala, R. A. Vishwakarma and P. P. Singh, RSC Adv., 2014, 4, 50208; (f) F. Xie, Z. Zhang, X. Yu, G. Tang and X. Li, Angew. Chem., Int. Ed., 2015, 54, 7405; $(g)$ K. Zhang, X.-H. Xu and F.-L. Qing, J. Org. Chem., 2015, 80, 7658; (h) K. Matsuzaki, K. Okuyama, E. Tokunaga, N. Saito, M. Shiro and N. Shibata, Org. Lett., 2015, 17, 3038; (i) F. Wang, X. Yu, Z. Qi and X. Li, Chem.-Eur. J., 2016, 22, 511; (j) L. A. Smyth, E. M. Phillips, V. S. Chan, J. G. Napolitano, R. Henry and S. Shekhar, J. Org. Chem., 2016, 81, 1285.

9 (a) J. P. H. Charmant, A. M. Dyke and G. C. Lloyd-Jones, Chem. Commun., 2003, 381; (b) Z. Zhao, J. Messinger, U. Schön, R. Wartchow and H. Butenschön, Chem. Commun., 2006, 3007; (c) K. Barta, G. Franciò, W. Leitner, G. C. Lloyd-Jones and I. R. Shepperson, Adv. Synth. Catal., 2008, 350, 2013; (d) A. M. Dyke, D. M. Gill, J. N. Harvey, A. J. Hester, G. C. Lloyd-Jones, M. P. Muñoz and I. R. Shepperson, Angew. Chem., Int. Ed., 2008, 47, 5067; (e) M. Kruck, M. P. Munoz, H. L. Bishop, C. G. Frost, C. J. Chapman, G. Kociok-Köhn, C. P. Butts and G. C. Lloyd-Jones, Chem.-Eur. J., 2008, 14, 7808; $(f)$ G. Werner, C. W. Lehmann and H. Butenschön, Adv. Synth. Catal., 2010, 352, 1345; (g) G. Werner and H. Butenschön, Eur. J. Org. Chem., 2012, 3132; (h) G. Werner and H. Butenschön, Organometallics, 2013, 32, 5798.

10 X.-H. Xu, X. Wang, G.-K. Liu, E. Tokunaga and N. Shibata, Org. Lett., 2012, 14, 2544.

11 For selected reviews, see: (a) C. M. Gampe and E. M. Carreira, Angew. Chem., Int. Ed., 2012, 51, 3766; (b) P. M. Tadross and B. M. Stoltz, Chem. Rev., 2012, 112, 3550; (c) A. Bhunia, S. R. Yetra and A. T. Biju, Chem. Soc. Rev., 2012, 41, 3140; (d) C.-L. Sun and Z.-J. Shi, Chem. Rev.,
2014, 114, 9219; (e) S. S. Bhojgude, A. Bhunia and A. T. Biju, Acc. Chem. Res., 2016, 49, 1658; (f) R. Karmakar and D. Lee, Chem. Soc. Rev., 2016, 45, 4459.

12 D. Qiu, J. He, X. Yue, J. Shi and Y. Li, Org. Lett., 2016, 18, 3130.

13 (a) X.-H. Xu, G.-K. Liu, A. Azuma, E. Tokunaga and N. Shibata, Org. Lett., 2011, 13, 4854; (b) X.-H. Xu, M. Taniguchi, A. Azuma, G.-K. Liu, E. Tokunaga and N. Shibata, Org. Lett., 2013, 15, 686; (c) X.-H. Xu, M. Taniguchi, X. Wang, E. Tokunaga, T. Ozawa, H. Masuda and N. Shibata, Angew. Chem., Int. Ed., 2013, 52, 12628; (d) C. Chen, X.-H. Xu, B. Yang and F.-L. Qing, Org. Lett., 2014, 16, 3372; (e) K. Zhang, X.-H. Xu and F.-L. Qing, J. Org. Chem., 2015, 80, 7658; (f) L.-N. Hua, H. Li, F.-L. Qing, Y. Huang and X.-H. Xu, Org. Biomol. Chem., 2016, 14, 8443. 14 For recent examples, see: $(a)$ R. Li, H. Tang, H. Fu, H. Ren, X. Wang, C. Wu, C. Wu and F. Shi, J. Org. Chem., 2014, 79, 1344; (b) B. Rao, J. Tang, Y. Wei and X. Zeng, Chem.-Asian J., 2016, 11, 991; (c) R. Kranthikumar, R. Chegondi and S. Chandrasekhar, J. Org. Chem., 2016, 81, 2451; (d) B. Rao, J. Tang and X. Zeng, Org. Lett., 2016, 18, 1678; (e) P. Gouthami, R. Chegondi and S. Chandrasekhar, Org. Lett., 2016, 18, 2044; $(f)$ R. Samineni, P. Srihari and G. Mehta, Org. Lett., 2016, 18, 2832.

15 For recent examples, see: (a) E. Yoshioka, H. Tanaka, S. Kohtani and H. Miyabe, Org. Lett., 2013, 15, 3938; (b) Y. Zhou, Y. Chi, F. Zhao, W.-X. Zhang and Z. Xi, Chem.Eur. J., 2014, 20, 2463; (c) Y. Zeng and J. Hu, Chem.-Eur. J., 2014, 20, 6866; (d) B. Rao and X. Zeng, Org. Lett., 2014, 16, 314; (e) M. Pawliczek, L. K. B. Garve and D. B. Werz, Org. Lett., 2015, 17, 1716; (f) A. C. Wright, C. K. Haley, G. Lapointe and B. M. Stoltz, Org. Lett., 2016, 18, 2793; $(g)$ Y. Li, C. Mück-Lichtenfeld and A. Studer, Angew. Chem., Int. Ed., 2016, 55, 14435.

16 For recent examples, see: (a) T. R. Hoye, B. Baire, D. Niu, P. H. Willoughby and B. P. Woods, Nature, 2012, 490, 208; (b) D. Rodríguez-Lojo, A. Cobas, D. Peña, D. Pérez and E. Guitián, Org. Lett., 2012, 14, 1363; (c) H. Yoshida, R. Yoshida and K. Takaki, Angew. Chem., Int. Ed., 2013, 52, 8629; (d) C. E. Hendrick, S. L. McDonald and Q. Wang, Org. Lett., 2013, 15, 3444; (e) C. Shen, G. Yang and W. Zhang, Org. Lett., 2013, 15, 5722; (f) F.-L. Liu, J.-R. Chen, Y.-Q. Zou, Q. Wei and W.-J. Xiao, Org. Lett., 2014, 16, 3768; $(g)$ S. Yoshida, T. Yano, Y. Misawa, Y. Sugimura, K. Igawa, S. Shimizu, K. Tomooka and T. Hosoya, J. Am. Chem. Soc., 2015, 137, 14071; (h) Z. Chen and Q. Wang, Org. Lett., 2015, 17, 6130; (i) Y. Li, S. Chakrabarty, C. Mück-Lichtenfeld and A. Studer, Angew. Chem., Int. Ed., 2016, 55, 802; (j) Y. Li, D. Qiu, R. Gu, J. Wang, J. Shi and Y. Li, J. Am. Chem. Soc., 2016, 138, 10814. 17 For a pioneering work of synthesis of $\mathrm{SOCF}_{3}$-containing aromatics by aryne insertion, see: Z. Liu and R. C. Larock, J. Am. Chem. Soc., 2005, 127, 13312. 